\title{
LA JERARQUÍA ANGÉLICA Y LAS GIUDADES DE ESMERALDA
}

\section{Francisco Martínez Albarracín}

Recibido: 12/03/2018. Aceptado: 15/07/2018.

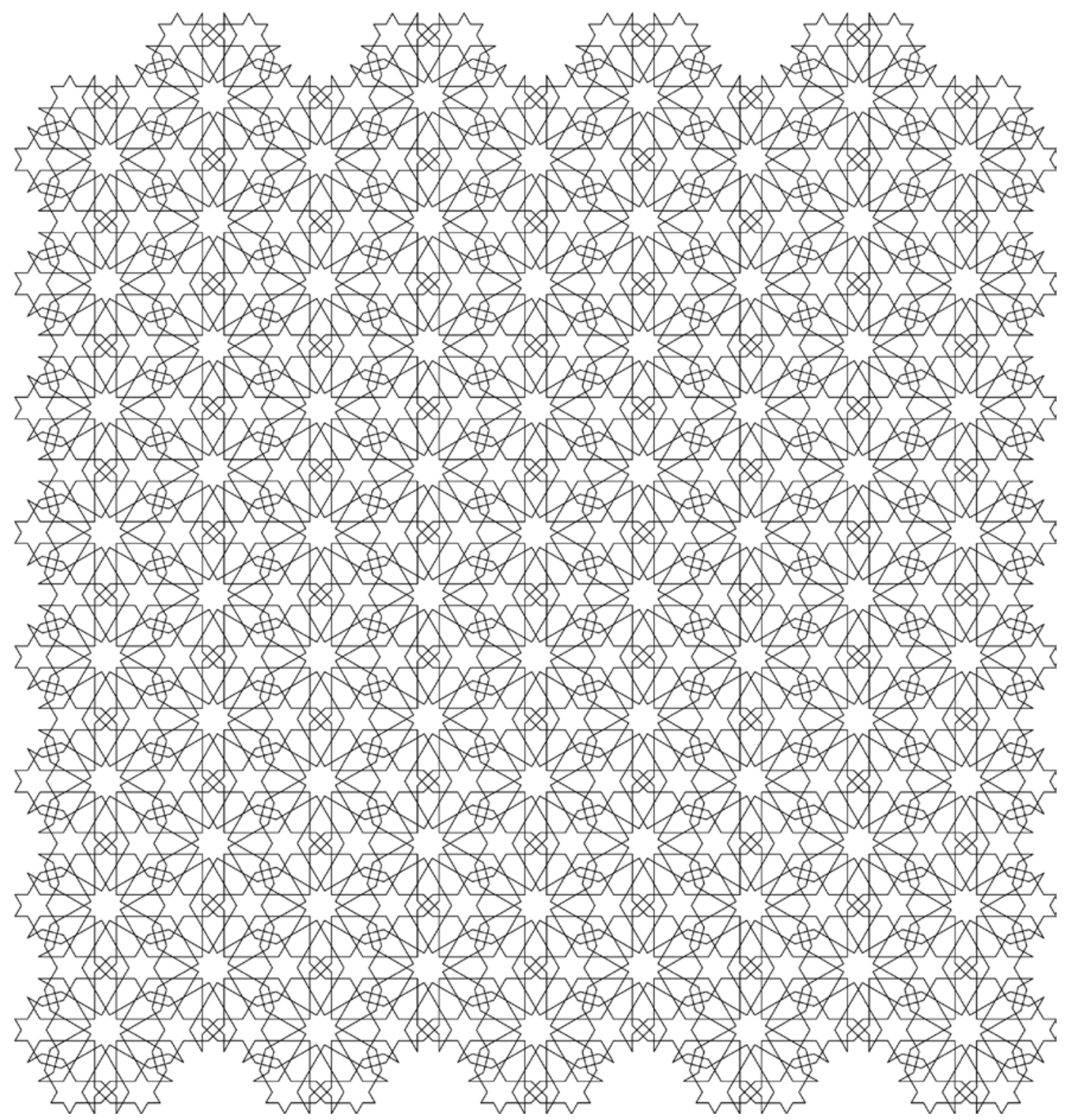


Resumen: Este artículo, todo él inspirado en Henry Corbin, tiene dos partes principales: en la primera, resumimos la doctrina sobre las jerarquías angélicas del Pseudo-Dionisio, mientras que en la segunda nos ocupamos del importante papel que tiene la angelología en la obra del filósofo francés, con alusiones al mundo imaginal y, especialmente, al significado del Ángel en la teosofía islámica y sus posibles analogías con la mística cristiana.

Palabras clave: Ángel, Henry Corbin, Pseudo-Dionisio Aeorpagita, Mundo Imaginal, Teosofia Islámica, Mística.

Abstract: This article, completely inspired by Henry Corbin's thought, has two main parts: In the first one, we will summarize Pseudo-Dionysius's doctrine on the hierarchies of angels and, in the second one, we will investigate the important role that angelology plays in Corbin's work, his allusions to the imaginal world and, specially, his allusions to the meaning of Angel in Islamic theosophy and its possible parallels with Christian mysticism.

Key words: Angel, Henry Corbin, Pseudo-Dionysius the Aeropagite, Imaginal World, Islamic Theosophy, Mysticism.

"Dios no tiene semejante (mit $)$, pero tiene una imagen (mitāl)" (Lāhīğì).

"Cada vez que sube de ti una llama, una llama desciende del cielo hacia ti"'.

1 Esto escribe Henry Corbin comentando una visión de Nağmuddīn Kubrā: "Estando en Egipto en una aldea ribereña del Nilo, me enamoré apasionadamente de una joven. Pasé varios días sin tomar alimento ni bebida, de modo que la llama de amor adquirió en mí una intensidad extraordinaria. Mi aliento exhalaba llamas de fuego. Y cada vez que exhalaba ese fuego, desde lo alto del cielo se exhalaba igualmente un fuego que venía al encuentro de mi propio aliento. Los dos resplandores se unían entre el cielo y yo. Durante largo tiempo no supe quién estaba allí donde los dos resplandores se unían. Finalmente comprendí que era mi testigo en el cielo". Henry Corbin se refiere igualmente a una visión similar que tuvo 'Ayn al-Qozāt Hamadānī (†525/1131): "En esta estación mística vi una luz que emanaba del Ser divino, y vi simultáneamente una luz que se elevaba de mí mismo. Las dos luces se encontraron y se unieron, y hubo una forma de tal belleza que quedé deslumbrado por algún tiempo" (ambas citas en Henry Corbin, El hombre de luz en el sufismo iranio, Siruela, Madrid, 2000, pp. 101 y 164). 


\section{INTRODUGGIÓN}

Hay tres maneras de mirar al cielo, nos recuerda Sohravardī: con los ojos corporales, con "los ojos del cielo" -como hacen los astrónomos- y "con la mirada interior del alma" (H. Corbin). Esta es la que contempla los cielos invisibles" ${ }^{2}$, el mundo del Malaküt, el mundus imaginalis, la mítica ciudad de Hurqalya, el ámbito de la revelación y la teofanía.

Leemos en el Gāyat al-Hakìm (o El objetivo del sabio, el Picatrix latino): "Guíame con tu sabiduría, protégeme con tu fuerza, hazme comprender lo que no comprendo... Habita en mi corazón con la energía que emana de tu noble entidad espiritual, que no se separa de mí, y con una luz que me sirva de guía en todos mis propósitos"”. Son palabras que su Naturaleza Perfecta le dice a Hermes, enseñándole cómo invocarla.

Los ángeles aparecen por doquier en las tradiciones espirituales y muy especialmente en el mundo iranio y en las religiones abrahámicas. "Una de las características de la angelología mazdeísta consiste en dar a cada uno de sus Arcángeles y de sus Ángeles una flor como símbolo"4. En las cosmogonías y teogonías órficas se describe a Fanes (el primer origen de todo, antes del segundo comienzo en la edad de Zeus) con rasgos angélicos: muy bello, andrógino, una figura de luz resplandeciente, con alas doradas sobre sus hombros, creador de la raza divina y, como se dice en un fragmento órfico (el número 85), "portando dentro de sí la venerada simiente de los dioses"5.

En el Evangelio gnóstico del siglo segundo Diálogo del Salvador, Mateo dice a su Maestro: "Señor, deseo [ver] ese lugar de vida, [ese lugar] el cual no tiene tinieblas, sino [luz] pura. Y Jesús le responde: "Todo aquel que se ha conocido a sí mismo lo ha visto".

Habitamos en el mundo exterior, pero estamos habitados por un mundo interior. Es el mundo del ángel. A él vamos a intentar acercarnos en las líneas que siguen.

2 El cielo como símbolo de lo suprasensible. Apropiado recordar las palabras de Nağmoddīn Kobrā: el cielo que el místico contempla, en la visión de lo suprasensible, no es nuestro cielo exterior: «No, -cito- hay en lo suprasensible otros cielos más sutiles, más azules, más puros, más brillantes, sin número ni límite». Y nos recuerda que, cuanto más nítido y transparente se vuelve nuestro corazón, más hermoso es el cielo que se nos muestra. Cielo sin límites, como la Simplicidad y Unicidad divina es sin límite. Por eso concluye: «Nunca pienses, pues, que más allá de lo que has alcanzado, no hay nada más, siempre hay algo más elevado». Cf. id., p. 75. De esto se trata, pues, del descubrimiento de los cielos del alma.

3 Cf. Corbin, H., El hombre y su ángel. Iniciación y caballería espiritual, Destino, Barcelona, 1995, pp. 61-62.

4 Cf. Corbin, H., Cuerpo espiritualy Tierra celeste, Siruela, Madrid, 1996, p. 62.

5 Cf. Guthrie, W.K.C., Orfeo y la religión griega. Siruela, Madrid, 2003, p. 131. 


\title{
LA JERARQUÍA ANGÉLICA EN EL PSEUDO-DIONISIO AREOPAGITA ${ }^{6}$
}

\author{
"No podemos conocer nada del otro Aion si no nos es \\ revelado por espíritus celestiales superiores" (Pierre- \\ Jean Olieu, conocido como Olivi). \\ "Divinizarse es nacer Dios en nosotros. Nadie podría \\ entender, y menos practicar, las virtudes recibidas de \\ Dios si no hubiese ya comenzado a estar en Dios"

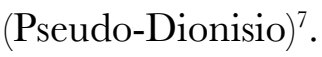

La palabra jerarquía alude aquí "al conjunto de realidades sagradas", pues Dionisio entiende por ella "un orden sagrado, un saber y actuar lo más próximo posible a la Divinidad". "Orden, entendimiento y acción constituyen las jerarquías"8.

6 Para la historia de la angelología son muy valiosos los libros de los profetas Daniel y Ezequiel y, desde luego, los de Enoc y Esdras IV. En este apartado nos ocupamos de la primera reflexión cristiana sobre los ángeles, muy influida de neoplatonismo y de enorme repercusión posterior, por ejemplo en la obra de Santo Tomás de Aquino.

7 Pseudo-Dionisio Areopagita, La jerarquía eclesiástica (en adelante, EH), II, 1. (Obras Completas, B.A.C., Madrid, 1990, p. 197).

8 Cf. La ferarquía celeste (CH), I, 3; III, 1. (Obras Completas, B.A.C., pp. 132 y 192). Además la jerarquía humana en la Iglesia (obispos, presbíteros, diáconos) imita a la triple jerarquía celeste. Por lo demás, la tríada neoplatónica está presente por doquier: existencia, vida, inteligencia; purificación, iluminación, perfección; ser, poder, acción; etc.

Conocida es la distinción entre los tres mundos en la metafísica de las principales tradiciones sagradas: el cielo o mundo divino y arquetípico, el mundo intermediario y la tierra o mundo inferior. Distinción macrocósmica a la que correspondería perfectamente, en el plano personal, la triple distinción del alma de Nağmuddīn Kobrā: así, el alma-conciencia (nafs lawrwāma), el alma censora, la inteligencia ("aql) "de la que hablan los filósofos", estaría entre la nafs ammāra (alma dominada por las pasiones, yo inferior, sombra, envoltura tenebrosa -son todas ellas expresiones con las que la traduce o explica Henry Corbin-) y la nafs motma'yanna (el alma pacificada, cabe decir, nuestro yo superior, el Sí mismo, o nuestro verdadero rostro). También Platón distinguía entre el alma pasional, la impulsiva y la intelectual; sólo esta última era, según él, inmortal (cf. Henry Corbin, El hombre de luz, p. 83).

Por lo demás, tanto para Ibn Arabi como para la gnosis ismailí, el ser humano es un ser intermedio: entre el ser y el no ser, entre la luz y las tinieblas, para el šayj al-akbar; ángel en potencia o demonio en potencia para la gnosis ismailí (cf. id., p. 109). 
Dos cosas consideraremos brevemente aquí: qué son los Ángeles y cómo queda definida y estructurada por él su jerarquía. Pero antes conviene decir que, para el Pseudo-Dionisio, si bien la "capacidad contemplativa" de nuestra mente es inmensa, el Rayo divino sólo podrá iluminarnos mediante los velos de los símbolos y figuras que aparecen en los textos sagrados y la liturgia; por otra parte la hermosura sensible "es signo de misterios sublimes"9. Y Henry Corbin nos recuerda: "La afirmación de que a todo lo que es aparente, literal, exterior, exotérico (zāhir) corresponde algo oculto, espiritual, interior, esotérico (bātin), constituye la reivindicación escrituraria que está en la base misma del chiísmo como fenómeno religioso"10. De manera muy poética nos dirá Sohravardī, en uno de sus relatos visionarios (es el maestro el que habla a su discípulo): «Sabe que la mayor parte de las cosas de las que tus sentidos son testigos, son otros tantos «rumores de las alas de Gabriel» ${ }^{11}$.

El que muy probablemente fuera un monje sirio fuertemente influido por Proclo ve a los Ángeles como santas inteligencias que carecen de figuras y trascienden toda materialidad. Dios los reviste de su propia forma y les dispensa su luz. "Espejos transparentes", reciben esa luz y la transmiten en tanto tienen por fin "lograr en las criaturas" "la semejanza y unión con Dios"12. "Actúan incesantemente a imitación de Dios" y viven en la "morada de la Luz"13. De igual modo en el léxico ismailí la expresión que los designa es "N $\mathcal{N} r$ sa sacānī, Forma de Luz traslúcida, resplandeciente y ligera a la vez" ${ }^{14}$.

En ocasiones los equipara a la Sabiduría divina, que es simple y multiforme (cf. Ef., 3, 10). "Tienden a concentrarse" en el "amor de Dios", pues Le ven directamente. Cooperadores de

9 Cf. Pseudo-Dionisio, CH, I, 3 (B.A.C., pp. 120-121). "Todas las cosas pueden favorecer la contemplación", ya que en todas ellas "hay algo de belleza" (cf. II, 3-4) (B.A.C., 127 y 128). "Hay algo divino en todas las cosas", escribe Aristóteles en su Ética a Nicómaco. Esta frase entendemos que adquiere su sentido más hondo en Ibn 'Arabī y en su escuela. Así por ejemplo 'Abd al-Karīm Ğìlī escribe: "Cada cosa sensible tiene su Espíritu creado por el que se constituye su Forma. Como Espíritu de esa Forma, está con ella en la misma relación que el significado con la palabra. Este Espíritu creado (rūh $m a j l u \bar{q}$ ) tiene un Espíritu divino ( $r u \bar{h} h$ ilăh $\vec{\imath}$ ) por el que es constituido, y ese Espíritu divino es el Espíritu Santo" (citado por Henry Corbin en su obra La imaginación creadora en el sufismo de Ibn 'Arabī, Destino, Barcelona, 1993, pp. 283-284).

10 Corbin, H., La imaginación creadora en el sufismo de Ibn `Arabī, p. 99.

11 Sohravardī, S. Y., El encuentro con el ángel. Tres relatos visionarios comentados y anotados por Henry Corbin, Trotta, Madrid, 2002, p. 73.

12 Cf. CH., III, 1-2 (B.A.C., p. 132). El ángel nos proporciona "sentidos y órganos de luz", dirán los místicos persas (cf. Corbin, H., El hombre de luz, p 33).

13 Cf. CH., XIII, 4 y XV, 4 (B.A.C., pp. 173 y 181).

14 Cf. Corbin, H., Cuerpo espiritual, p. 304, nota 39. 
esa Luz que "purifica, ilumina y perfecciona"15. Además de su poder de discernimiento, otra característica de los ángeles es su capacidad para recogerse, "su concentración unificante, el replegarse armonioso e infatigable en torno a la propia identidad"16.

Recordemos que en Proclo el ángel es ante todo "revelador". Las manifestaciones de Dios, a quien nadie puede ver, se producen por medio de los ángeles. Idea esencial que vamos a encontrar igualmente en los autores sufies. Así por ejemplo, en la literatura persa, aparece la abubilla como símbolo de la inspiración del corazón. Dionisio se basa en Proclo cuando escribe que los ángeles son los "mensajeros y reveladores del silencio de Dios". Por eso han revelado visiones de misterios escondidos a este mundo, o divinas profecías. Y considera, igualmente, que la Ley fue dada Moisés por mediación angélica ${ }^{17}$.

Cuando hace referencia a su número nos dice que es infinito, o que solo Dios lo conoce (también Sohravardī habla de "luces infinitas"). Y cuando se refiere, en el último capítulo de su libro, a las imágenes figurativas que los representan afirma que "el símbolo del fuego es la mejor manera de expresar la semejanza que tienen con Dios los seres-inteligencias del Cielo"18. Destaco, además, sus referencias a los vientos, ríos, ruedas y carros; a la nube, los metales y piedras multicolores; a la forma humana y las figuras animales (león, buey, águilas, caballos). Alude al corazón como "símbolo de una vida deiforme" y al gusto, que tanta resonancia tendrá en sufismo, como figura de "la satisfacción del entendimiento cuando bebe hasta saciarse en los ríos de la Deidad" ${ }^{19}$. En Sohravardī, me permito recordarlo ahora, en su relato El Arcángel teñido de púrpura, el ángel aparece "con los rasgos de un sabio de eterna juventud, cuya blanca cabellera anuncia su pertenencia al mundo de la luz", aunque nada

15 Cf. CH., III, 2; IV, 2 (B.A.C., pp. 134 y 137).

16 Cf. id., XV, 4 y 5 (B.A.G., p. 181).

17 Cf. id., IV, 2 (B.A.C., p. 138); Sobre los Nombres divinos, 4.696 B.

18 Es en una de sus visiones, la que preludia y decide su viaje sin retorno hacia Oriente, donde Ibn "Arabī "ve el Trono divino sostenido por un número incalculable de refulgentes columnas de fuego" y un pájaro de extraordinaria belleza, que "vuela en círculos alrededor del Trono" le comunica la orden de partir hacia Oriente. Este pájaro, símbolo del ángel Gabriel, le acompañará y será su "guía celeste", que se le mostrara en otros lugares y con otras formas, sobre todo "«alrededor de la Ka'ba mística»" (cf. Henry Corbin, La imaginación creadora, pp. 66-67).

19 Cf. CH., o. c., XV, 2-3 (B.A.C., 178 y 180). "Dotados de muchas alas y muchos ojos" (cf. Ezequiel e Isaías). Hace también una curiosa referencia a "sus fuerzas reproductoras", cuando habla de los ceñidores con los que se los representa. Pero escribe Dionisio que "tienen el poder de dar la vida, de hacer crecer y llevar a perfección porque derraman lluvias [se refiere al símbolo de la nube] de entendimiento y llaman al seno que los recibe para que dé a luz criaturas nuevas" (cf. XV, 4 y XV, 6) (B.A.C., pp. 181 y 182-183). 
más se nos diga de su aspecto ${ }^{20}$. En palabras de Swedenborg «el cuerpo de cada Espíritu y de cada Ángel es la forma de su amor» ${ }^{21}$.

También me parece muy interesante la equiparación, que hace Dionisio, de Jesús con el Ángel, porque Jesús no sólo recibió órdenes de Dios "por medio de los ángeles" y fue confortado por ellos, sino que él mismo "es contado entre los ángeles de la revelación con el nombre de «Ángel del Consejo». ¿No fue Él en verdad un ángel por habernos anunciado lo que conoció del Padre?"22.

Pero pasemos ahora a considerar muy brevemente lo que dice de la jerarquía, teniendo en cuenta que sus nombres "significan los distintos modos de recibir la impronta de Dios" 23 . Tengamos en cuenta que cada jerarquía recibe su iluminación y conocimiento de las inmediatamente superiores ${ }^{24}$.

En cuanto a la primera (Serafines, Querubines, Tronos, por este orden), son "los más divinizados" y están "colocados inmediatamente junto a Dios y a su alrededor" 25 . Serafin "equivale a decir inflamado o incandescente"; también significa, entre otras cosas "incesante movimiento en torno a las realidades divinas", un movimiento circular, "continuo, firme y estable"26. Querubin significa "rebosante de sabiduría", mientras que los Tronos son portadores de Dios, viven siempre en Su presencia y connotan la idea de ascenso y elevación. Significan también el poder de estar abierto para recibir a Dios. Caracteriza a estos ángeles su carácter

20 Cf. Sohravardī, o. c., p. 69.

21 Citado por Corbin. Cf. Cuerpo espiritual, p. 125.

22 Cf. CH., IV, 4 (B.A.C., p. 140). Escribe Henry Corbin: "Como en la visión de Hermes, la angelofanía está asociada con el símbolo del «sol de medianoche», de la noche luminosa, porque la Primera Inteligencia, el Ángel-Logos, es la teofanía inicial y primordial del Deus absconditus" (cf. El hombre de luz, p. 129).

23 Cf. CH, VII, 1 (B.A.C., p. 145).

24 Esta idea, de claro origen neoplatónico, se repetirá en las angelologías de los autores musulmanes. Por ejemplo, en Ibn Arabi, que nos habla de cinco Presencias o Descensos (hadarāt, "determinaciones o condiciones de la Ipseidad divina en las formas de sus Nombres"), la segunda y la tercera son las que corresponden al mundo angélico, más precisamente, a los Espíritus (ta ayyunāt rūhiyya) y a las Almas (ta ayyunāt nafsiyya), mientras que la cuarta corresponde al mundus imaginalis. Pero queremos subrayar aquí que cada mundo, cada Descenso, es la epifanía del mundo superior que le precede en el rango; por eso puede decirse que el mundo humano "comprende al conjunto de los mundos" (cf. Henry Corbin, La imaginación creadora, pp. 412-413).

25 Cf. CH, VI, 2 (B.A.C., 143-144).

26 El Maestro Eckhart se refiere a la Sabiduría, en tanto que atributo divino, como motus sine motu y Proclo explicaba la vida como el eterno movimiento (automovimiento) y la identidad estable. Además Proclo se refería a los ángeles diciendo que son el "vestíbulo de Dios". 
contemplativo, su perfección y pureza supremas, por estar "llenos de una luz superior que excede todo conocimiento" ${ }^{\prime 2}$.

Refiriéndose a la segunda jerarquía, intermedia (Dominaciones, Virtudes, Potestades), nos dice que sus nombres están relacionados con el atributo de la potencia, del poder, y Dionisio los comenta en relación con el señorío, la elevación, la semejanza y la firmeza. A ellos alude la expresión bíblica "Señor de los ejércitos"28.

A los Principados, Arcángeles y Ángeles (la última jerarquía) también los llama deiformes. Una deiformidad simbolizada por sus "vestidos luminosos e incandescentes" "29 "Principado" hace referencia al mando y "a la capacidad de orientarse plenamente hacia el Principio" "sobre todo principio" y "guiar a otros hacia Él”. Los arcángeles ocupan un lugar intermedio, pues en cada jerarquía hay tres poderes, y los ángeles, en fin, están más cerca de nosotros y del mundo. Expresamente dice Dionisio que son "los que nos hacen manifiesta la revelación". Velan por la jerarquía humana y les son asignadas las naciones ${ }^{30}$.

Esta distinción o jerarquía triádica aparecerá claramente en Sohravardī al igual que en la angelología islámica y sufí, que distingue fundamentalmente entre los angeli intellectuales (superiores) y los angeli caelestes (que rigen los cielos), pero los tres órdenes son "los karūbiyyūn, querubines, Logoi o Palabras superiores absolutamente trascendentes; los Logoi intermedios, regentes de las Esferas; finalmente, los Logoi menores que son los humanos, ángeles o demonios en potencia"31.

27 Cf. CH, VII, 1; VII, 2; XIII, 3 (B.A.C., pp. 146, 148 y 171). Su proximidad es su máxima capacidad de recibir a Dios sin mediación. Son las "luces más secretas" al ser "más intelectuales", "simplificadoras" y "unificantes" (cf. X, 1) (B.A.C., p. 162). Santo Tomás de Aquino, que sigue al que llama San Dionisio, se refiere a esta primera jerarquía comparándolos con los más íntimos cortesanos de un Rey y dice que tienen un "conocimiento inmediato" de los "secretos divinos" (cf. S.Th., I, q. 108, a. 6). 28 Y más concretamente a las "virtudes” o poderes, según el Pseudo-Dionisio. Para la expresión bíblica, ver Dan., 3, 61; Ps., 24, 10; 80, 5; 103, 21, etc.

29 Cf. La jerarquía celeste, o. c., XI, 1 y XV, 4 (B.A.C., pp. 157 y 181).

30 Cf. id., IX, 1 y IX, 2 (B.A.C., pp. 157 y 158). También el ángel Sraosha (en la nota 48 veremos que es considerado además el ángel de la iniciación), en el zoroastrismo, "vela sobre el mundo adormecido" y es la "cima de una sodalidad de migradores que «velan» sobre el mundo y por el mundo"; se les llama en avéstico "drigu", término que alude a su "pobreza sacral" y que es origen del término derviche que significa "pobre de espíritu". Cf. Corbin, H., El hombre de luz, p. 72.

31 Cf. Corbin, H. El hombre y su ángel, p. 27. Para Kobrā el Malakūt es el mundo de los ángeles o animae caelestes, "lo esotérico de los cielos visibles", mientras que el Ğabarūt sería "el mundo de los querubines" o "de los Nombres divinos" cf. Henry Corbin, El hombre de luz, p. 94). 
Al final de su libro, dice el autor, graciosa y sinceramente, aludiendo a lo incompleto de su exposición que se encuentra "perdido cuando se trata de entender las realidades trascendentes", pues no quería hacer "un tratado demasiado largo" y sí "tributar" un "respetuoso silencio a los misterios" donde no alcanza su entendimiento ${ }^{32}$.

\title{
SOBRE HURQALYA Y EL MUNDO IMAGINAL
}

\author{
"Hay [una] Majestad inaccesible de la Belleza, y hay \\ [una] Belleza fascinante de la Majestad inaccesible" \\ (Henry Corbin).
}

Hacíamos al inicio una referencia al orfismo. Ciertamente en los Fragmentos órficos podemos encontrar analogías con lo que significa el mundo de Hurqalya, pues los órficos consideraban a las estrellas mundos habitables. Ya en la época grecorromana, como lo confirman diversos testimonios, existía la creencia de que la Vía Láctea era la morada de las almas, creencia, por lo demás, común a otros pueblos. Pero es el fragmento número 22 el que nos transmite este aserto de los Placita: "Heraclides (o sea, Heraclides del Ponto, contemporáneo de Platón) y los pitagóricos dicen que cada una de las estrellas es un mundo, tierra y aire circundante, todas en el éter infinito. Estos dogmas son corrientes en los textos órficos, pues hacen un mundo de cada una de las estrellas" 33 . Y Proclo, que distinguía entre ángeles creadores, generadores y salvadores, nos dice que las almas han sido "sembradas" en las estrellas. Doblemente oportuna nos parece esta referencia astral, ya que la imaginación creadora puede ser considerada astrum in homine, según la expresión de Ryland.

32 Cf. $C H$, XV, 9 (B.A.C., pp. 185-186). Bien conocida es la importancia, en el Pseudo-Dionisio, de la dimensión apofática, de la Tiniebla divina a la que alude su teología mística. No carece de interés relacionarlo con el color negro y la luz negra de la mística persa (igualmente con el simbolismo del sol negro o sol de medianoche). Así, comentando un dístico de La rosaleda del misterio escribe Lāhīğĩ: "El color negro, si comprendes, es luz de la pura Ipseidad. En el interior de esta tiniebla está el Agua de la Vida" (citado por Henry Corbin, cf. El hombre de luz, p. 127). Y aplicado al ser humano, la dimensión de la supraconciencia (sirr, jāfi), en Nağmuddīn Kobrā, se anuncia simbólicamente por la "luz negra" (cf. id., p. 113).

"Noche luminosa, mediodía oscuro" canta el poeta de La rosaleda del misterio. Y la noche oscura del poeta castellano: "Noche amable más que la alborada".

33 Guthrie, W.K.C., Orfeo y la religión griega, p. 246. 
Pero es en Platón donde encontramos, en el Timeo, el texto más significativo:

"Cuando el Demiurgo hizo por vez primera las almas individuales, las hizo «iguales a las estrellas en número, y asignó cada una a una estrella», y mientras estaban aún en las estrellas les enseñó la naturaleza del universo y cuál sería la suerte que les correspondería, es decir, ser implantadas en cuerpos. «Cuando hubieran sido implantadas en cuerpos por las obras de la necesidad... ante todo la facultad de sensación, la misma para todos, sería naturalmente suscitada en ellas como resultado de impresiones violentas, y segundo el amor, mezclado de placer y dolor, y además de ello el temor y la cólera y todas las pasiones que o bien resultan de éstas o son sus contrarias. Si dominaban esas pasiones, vivirían con rectitud, pero, si eran dominadas por ellas, vivirían de modo no recto; y la que hubiera vivido bien su tiempo señalado viajaría otra vez para morar en su propia estrella y vivir una vida bienaventurada según su verdadera naturaleza»" ${ }^{34}$.

Hurqalya es una tierra en la que lo imposible se hace posible, en palabras de "Abd al-Karīm Gìili. Es el "octavo clima", "el país del no-donde", al que se accede a través la "Fuente de la vida", en el Centro del mundo. Por eso se dice simbólicamente que es precisamente la montaña de $Q \bar{a} f$, "como límite de nuestro mundo", la que "marca el comienzo del mundus imaginalis".

Como afirma Dā’ùd Qayșarī: "Se le llama mundus imaginalis porque contiene las Formas imaginales de todo cuanto existe en el mundo, y porque es lo imaginal de todas las Formas de los individuos y de las esencias que existen en el plano del conocimiento divino"35. Por su parte Ibn 'Arabī, en sus Iluminaciones de la Meca, afirma que con un resto de la arcilla con la que fue creado Adán, o más bien de la levadura de esta arcilla, se creó una tierra cuya denominación árabe se puede traducir como «Tierra de la Realidad Verdadera» o como «Tierra de la Verdad Real». Sería "una tierra inmensa que contiene a su vez Cielos y Tierras, Paraísos e Infiernos".

Henry Corbin lo expone magistralmente: El mundus imaginalis, contemplado por los peregrinos del espíritu, es, en definitiva, "un universo que mantiene una analogía completa tanto con la sustancia corporal, porque posee forma, dimensiones y extensión, como con la sustancia separada o inteligible, porque está esencialmente formado de luz (nürān $\vec{\imath}$. Es simultáneamente materia inmaterial e incorporeidad corporalizada en cuerpo sutil. Es el límite que las separa y que al mismo tiempo las une. Por esta razón, este universo se denomina generalmente barzah

34 Citado por Guthrie, W.K.C. Cf. Orfeo y la religión griega, p. 247. Sustituyo en el texto la palabra Creador por la de Demiurgo.

35 Corbin, H.: Cuerpo espiritual, p. 170. 
(pantalla, límite, intervalo, intermundo) en la teosofía especulativa del chiismo"36 .

«Penetré -escribe Ğìlì- en la ciudad de la Tierra maravillosa37, cuya longitud y anchura son enormes, y sus habitantes tienen un conocimiento de Dios que no posee ninguna otra criatura. No hay entre ellos ningún hombre que se permita la menor distracción. Su suelo está hecho de pura y blanquísima harina de trigo; el Cielo es de color verde esmeralda. Sus habitantes sedentarios son de una raza pura y de una elevada nobleza; no reconocen más rey

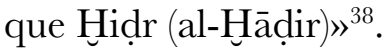

La Obra alquímica, el «Espejo de los sabios», "mediante los efectos físicos que provoca en quien la medita e interioriza", se lleva también a cabo esencialmente en la tierra de Hūrqalyā. Pues la alquimia transmuta los elementos terrenales en elementos sutiles ${ }^{39}$. Por eso, "esta tierra de Hūrqalyā, que la meditación del creyente alimenta con su propia sustancia, es simultáneamente la tierra de la que obtiene su meditación y con la que elabora los elementos sutiles de su cuerpo de resurrección”"

Siguiendo la enseñanza del šayh 'Abū l-Qāsim Huān Ibrāhīmī (también llamado Sarkār Āgā) aunque se haya designado acertadamente a Hūrqalyā «como el "octavo clima" que se encuentra más allá de nuestro mundo», «no hay que olvidar que se encuentra también en lo invisible de nuestro propio mundo» ${ }^{41}$. Por eso se ha dicho que el mundo imaginal es también "el comienzo de la «fortaleza del alma»" ${ }^{42}$.

36 Corbin, H., Id., pp. 103-104.

37 También llamada, en el mismo texto, por Ğìlī «Tierra de la perfección» y «mina original de la Belleza».

38 A propósito del viaje del Extranjero y la conversación con Haạdir, en la antología de textos citada del libro Cuerpo espiritual y Tierra celeste, cf. pp. 180-181.

39 Cf. id., p. 122. "Nuestro método - afirma Nağmuddīn Kobrā- es el método de la alquimia; se trata de extraer el organismo sutil de la luz de las montañas bajo las cuales yace prisionero".

40 Id., p. 109.

41 Citado por Corbin en la segunda parte de su libro Cuerpo espiritualy Tierra celeste, p. 260.

42 Cf. Sohravardī, S. Y., p. 123, nota 23. 


\title{
ALGUNOS ASPEGTOS ESENGIALES DEL ÁNGEL EN LA OBRA DE HENRY GORBIN
}

\author{
"Yo soy la luz de tu Señor" (Rūmī). \\ "Tú eres el Espíritu que me alumbró y al que, a \\ su vez, mi pensamiento alumbra" (Sohravardīe \\ Ismāêll de Ankara).
}

Acabamos de referirnos al mundo imaginal; pues bien, hay que decir que los ángeles representan la Imaginación en estado puro. Ellos habitan las ciudades de esmeralda ${ }^{43}$, Ğābalqā y Ğābarsā. Precisando un poco más, "para Ibn 'Arabī el Ángel representa la correlación esencial entre la forma de la teofanía y la forma de aquel a quien esa teofanía se muestra"44. Por eso, es en el mundo imaginal donde puede operarse el deseado encuentro entre el hombre y su ángel ${ }^{45}$. Y por eso en el sueño también nos es dado, a veces, contemplar algo del mundo del ángel, pero este mundo nos llama a la interioridad, al despertar.

Los Ángeles atraviesan nuestro mundo sin que los veamos con nuestros ojos carnales. Como se dice en la teosofía ismailí, el ángel es «aquel al que no puede alcanzar la osadía de los pensamientos» ${ }^{46}$.

El mundo del ángel es el mundo del alma. En cierto sentido, podemos considerar que "cada estado espiritual, cada función, cada sentimiento, cada acto, tiene su entidad espiritual, su «ángel», que se manifiesta en la luz que le es propia"47. Recordemos el "todo está lleno de

43 El sabio, el guía interior, en la visión del místico, tiene en sus manos "una tablilla de esmeralda" (cf. Corbin, H., El hombre de luz, p. 36).

44 Corbin, H., La imaginación creadora, pp. 79-80. En efecto, y es importante recordarlo, pues para Ibn 'Arabī como para otros maestros (por ejemplo Rūzbehān) "las teofanías de los Nombres y los atributos" están "siempre esencialmente en correspondencia con el estado espiritual de aquel a quien se muestran". Cf. El hombre de luz, p. 166, nota 108).

45 Pues la visión del ángel es "una percepción directa de lo suprasensible por el órgano del corazón" (cf. id., p. 119).

46 Cf. Cuerpo espiritual, p. 344, nota 11.

47 Cf. El hombre de luz, p. 117. Avicena coincide con Platón (con el Platón de la doctrina no escrita acerca de los dos principios metafísicos de lo real) cuando se refiere a "la doble dimensión de todo ser" venido a la existencia. Creo que esto corresponde, filosóficamente hablando, al relato mítico de la luz (o chispas de luz) atrapada en las tinieblas de la materialidad (el Canto de la Perla, al que hicimos referencia, es proverbial en este sentido y también la doctrina de Mani). Y cabe igualmente considerar el aspecto místico (y vital, existencial) que pone en juego nuestro grado de libertad, así como la necesidad de una purificación como inicio de la vía interior. 
dioses" de los filósofos presocráticos. Ángeles, potencias, que se generan y que generamos, que nos llaman y que son llamadas. La concentración, el silencio, el fuego del dikhr, la contemplación, nos acercan a esos ángeles, hermosos y en cierto modo terribles, que pulen nuestro corazón, afinan nuestro oído interior, preparan el Encuentro que se celebra en la eternidad.

Platón afirmaba que la verdadera experiencia filosófica (esa que Sohravardī vincula y relaciona con la mística) es como una llama que enciende otra llama. La llama del alma y la llama del ángel. Lo citábamos al inicio: "cada vez que sube de ti una llama, una llama desciende del cielo hacia ti".

Al hablar del Pseudo-Dionisio nos hemos referido antes a su papel de reveladores. Los Ángeles purificaban, iluminaban y perfeccionaban. En el sufismo esa función es la que corresponde al ángel en tanto que iniciador: $\mathrm{El}$ ángel es aquí quien dispensa una "revelación de los mundos superiores" y del camino espiritual "que hay que seguir para hacerse presente en esos mundos"48. En este sentido, su papel es análogo al de la Sophia, que se nos revela a cada uno en una Forma. Y es precisamente, como indica Corbin, la sofianidad de nuestro ser, tipificada en Maryam, lo que condiciona y hace posible en nosotros la visión del ángel ${ }^{49}$.

Pero hay otro aspecto que es esencial en toda la obra de Henry Corbin: el ángel es nuestro alter ego, el Gemelo celeste; más que un doble propiamente, lo entiende como "un complemento celestial trascendente" ${ }^{50}$, el principio transcendente de nuestra individualidad, "su individuación latente en el mundo del Misterio" (que Ibn ‘Arabī también llama Espíritu) nuestra Naturaleza Perfecta de la que habla el hermetismo ${ }^{51}$. Tenemos un Nombre en el Malakūt, lo tenemos en el Pensamiento divino; es nuestra hecceidad eterna (como repite Henry Corbin), recuperar esa Imagen, recrearla, embellecerla es nuestra tarea. Y ello conlleva iluminar también nuestra sombra. El versículo coránico $(28,88)$ : "todo perece salvo su rostro", puede ser interpretado como rescate de esa individualidad divina en nosotros: todo perece, salvo el rostro de luz de cada ser.

48 Cf. Sohravardī, S. Y.: o. c., p. 68. En relación con esta función iniciadora del ángel es oportuno referirse a la figura del ángel Sraosha, en el zoroastrismo, ángel que no pertenece a la héptada suprema de los Amahraspands, los santos inmortales o arcángeles, pero que, identificado en el Islam con Gabriel (también se corresponde con el ángel Serafiel), es la figura del "ángel-sacerdote”, ángel de la iniciación (walāyat) y está también caracterizado por su juvenilitas. Reside en el polo, en la estrella Polar, en la cima del monte Alborz (que equivale al monte Mehru). Cf. Corbin, H., El hombre de luz, p 70.

49 Cf. Corbin, H., La imaginación creadora, p. 201. Además, el alma mística se convierte en la "madre de su padre" (umm ab̄ì-hā), como en María o Fā.ima (cf. El hombre de luz, p. 39).

50 Cf. Corbin, H., El hombre de luz, p. 108. En cambio la sombra o envoltura tenebrosa, "lo que impide la reunión de la sicigia de luces no puede ser uno de sus elementos constitutivos". Cf. id., p. 110. 51 Esta Naturaleza está simbolizada, en el célebre Canto de la Perla de los Hechos de Tomás por las vestiduras que el príncipe recibe de sus padres y que tuvo que dejar cuando partió; vestiduras que no veía desde que era niño (cf. id., p. 40). 
Con palabras de nuestro autor: “¿Qué es el «ángel», en efecto, sino el mundo verdadero del hombre, su Naturaleza Perfecta que lo aguarda, pero cuya permanencia celestial, adquirida ya, continuamente le guía y le sostiene en el tiempo de su exilio? El «ángel» es, en el fondo, su esencia realizada" ${ }^{\prime 2}$.

A la pregunta que le hacen a Sócrates (en el Gàyat al-Hakìm o El objetivo del sabio, antes citado) acerca de qué es la Naturaleza Perfecta, la clave de la sabiduría, éste respondió: "es la entidad espiritual (o celestial, el Ángel, rūhāniyya) del filósofo, la que está unida a su astro, la que lo gobierna, le abre los cerrojos de la sabiduría, le enseña lo que es difícil, le revela lo que es justo, le sugiere cuáles son las llaves de las puertas, durante el sueño como durante el estado de vigilia" 53 .

El monje que firmaba sus obras con el nombre de Dionisio aludía a la Gracia como un "agua que comunica plenitud de vida", que "llega a las entrañas" formando "ríos inagotables"

En su libro de horas, Sohravardī escribe este precioso salmo, que titula Invocación (daßwat) a la Naturaleza Perfecta:

“¡Oh tú, mi señor y príncipe, mi ángel sacrosanto, mi precioso ser espiritual! Tú eres el padre que me engendra en el mundo del Espíritu ( $a b r$ rụhānī) y tú eres mi hijo en el mundo del pensamiento (walad mánawī). Estás exclusivamente dedicado, por permiso divino, al gobierno de mi persona. Tú eres aquel cuyo fervor intercede ante Dios, el Dios de los dioses, para compensar mi deficiencia. Tú que estás revestido de la más resplandeciente de las Luces divinas, que permaneces en la cima de los grados de la perfección, yo te imploro por Aquel que te ha colmado de esta nobleza sublime y que ha dispensado esta efusión de gracia inmensa. ¡Ah! ¡Ojalá te manifiestes a mí en el momento de la suprema Epifanía y me muestres la luz de tu Faz deslumbrante! Que seas para mí el

52 Corbin, H.: El hombre y su ángel, p. 12. Nuestro autor ha sido siempre un defensor de "la idea de la individualidad esencial e inamisible", idea para él indisociable de la angelología, por ser ella misma "fundamento de la idea del ángel en la misma medida en que es fundamentada por ella" (cf.: El hombre de luz, o. c., p. 110). En efecto, bien sabe Corbin que cada ángel es un individuo que agota su especie; una individualidad arquetípica, que le hace especialmente único. Si nada se repite en la creación, como pedía Leibniz, menos aún en la cima de los reinos y seres que van perfeccionando esa aludida singularidad.

53 Corbin, H., El hombre y su ángel, p. 59. Buscamos el Agua de la Vida. Avicena nos sugiere que se encuentra en "estas tinieblas en las proximidades del polo", como sugiere en su relato místico. No se aprende a encontrarla "simplemente de oídas" o "leyendo libros", como sugiere Corbin, pero es el anhelo el que nos lleva a ella, un anhelo que responde a un movimiento de la Gracia.

54 Cf. La Jerarquía celeste, II, 5 (B.A.C., p. 130). 
mediador ante el Dios de los dioses en la efusión de la luz de los Secretos místicos; que levantes de mi corazón las tinieblas de los velos, -esto te pido en nombre de su derecho sobre ti y de su rango en relación contigo" ${ }^{\circ 5}$.

Nosotros también formamos parte de la sociedad de los ángeles cuando nos consagramos -fieles de amor- al servicio de la verdad, de la causa divina ${ }^{56}$.

\section{UNIVERSO ANGÉLICO Y EXPERIENGIA ESPIRITUAL}

"Ante la aparición de una belleza sobrehumana, / ante esta Forma que florece del suelo como una rosa, / como Imagen que levanta la cabeza sobre el secreto del corazón..." (Rūmī).

"Hay luces que suben y luces que bajan. Las que suben son las del corazón; las que bajan, las del Trono. El ser creado es el velo entre el Trono y el corazón. Cuando este velo se rompe y en el corazón se abre una puerta hacia el Trono, lo semejante se precipita hacia su semejante" (Kobrā).

Los maestros hablan del mundo de Hūrqalyā para recordarnos a los seres humanos la necesidad que tenemos de la elevación espiritual. Es en esta misma tierra que habitamos donde debemos convertirnos en habitantes de la tierra de Hūrqalyā, en hūrqalyā $\overline{1}$. Hay que entrar en el templo interior para encontrarnos con el ángel. Sohravardī ha contado cómo, tras un periodo de agotamiento y adversidades que le causaba la reflexión sobre el problema del conocimiento, en uno de sus sueños o visiones, en un acontecimiento psico-espiritual producido en el lugar mítico de Ǧābarsā, se le apareció el Imam de los filósofos, Aristóteles, quien le dijo: «despiértate a ti mismo». Este despertar (la apertura del "ojo del corazón”, del "ojo del más allá" u "ojo barzají") es necesario para que aflore la verdadera experiencia

55 Citado en Henry Corbin, En Islam iranien. Aspects spirituels et philosophiques. 2. Sohravard̄̄ et les Platoniciens de Perse, Gallimard, Paris, 1971, p. 138-139. La traducción del francés es nuestra.

$56 \mathrm{Y}$ esto es precisamente lo que implica la idea de vocación, con todo lo que connota, tal vez lo que mejor recapitula, según Henry Corbin, lo que nos sugiere la idea del ángel. 
interior, la Aurora o el Oriente del alma, y pueda surgir ese «conocimiento presencial» ('ilm hudū $\bar{r} \overline{1}$ ), «conocimiento oriental» ('ilm išr $\bar{r} q \bar{\imath})$ o cognitio matutina ${ }^{57}$.

Hay que realizar un viaje para volver del exilio occidental. Nuestros conocimientos, meditados, interiorizados, han de transformarse en acontecimientos de nuestra alma. Es en nuestro corazón donde se produce el encuentro con el Ángel. "Para Qaysari -cito a Luce LópezBaralt, que a su vez cita a dos autores franceses-, el qalb, gracias a su posibilidad invertidora (taqallub), constituye un «intermundo entre lo visible y lo invisible, de donde emanan las potencias corporales y espirituales»" ${ }^{" 58}$.

Los místicos nos hablan de la paz que se alcanza al final del camino. Afirma Henry Corbin que, en la mística islámica, la Sakīna "es la quietud del alma, la paz interior, signo de la presencia directa", como en el caso de Moisés o de Muhammad ${ }^{59}$. De esta quietud y sosiego nos informa bien San Juan de la $\mathrm{Cruz}^{60}$. La verdadera religión es el vínculo, en cada uno de nosotros, entre la Tierra y el Cielo: El arca de la Sakīna (tābūt al-sākīna), la Luz de la Vida ${ }^{61}$.

57 Cf. Cuerpo espiritual y Tierra celeste, p. 109-110. También en San Juan de la Cruz encontramos esta distinción entre conocimiento matutino y vespertino, algo nada extraño si tenemos en cuenta, por ejemplo, los estudios de Luce López Baralt. Así comenta en su Cántico espiritual la expresión al monte y al collado: "a la noticia matutina y esencial de Dios, que es conocimiento en el Verbo divino" (monte) y "a la noticia vespertina de Dios" (collado), "que es sabiduría de Dios en sus criaturas y obras y ordenaciones admirables". El monte es más alto, igual que esa sabiduría (cf. Cánt. B, 36, 6-7).

58 Ver la revista El Azufre Rojo. Revista de estudios sobre Ibn Arabi, III, año 2016, p. 27, nota 37.

59 Corbin, H., El hombre y su ángel, o. c., p. 271, nota 49. Ante la visión del fuego del dikr, nos dice Kobrā, "el místico experimenta un sentimiento de ligereza interior, de expansión, de sosiego íntimo". 60 Ya hemos aludido antes a las relaciones que pueden establecerse entre San Juan de la Cruz y la mística sufi. Me refiero ahora tan sólo un par de puntos, íntimamente vinculados, que hacen referencia al desconocimiento y al desapego o pobreza más absolutos. Si hay un tiempo para la visión del ángel, también lo hay para ese deslumbramiento y ceguera que no se producen por "una extrema distancia", antes al contrario por "un exceso de proximidad": cuando se abre "el ojo de la visión interior -comenta Corbin-, los propios «sentidos suprasensibles» están entonces entenebrecidos". San Juan de la Cruz sabe por experiencia propia que la cima del conocimiento es una forma de desconocimiento ("si quieres saberlo todo, no quieras saber algo en nada"): "Entréme donde no supe, / y quedéme no sabiendo, / toda ciencia trascendiendo".

En cuanto a la pobreza espiritual, bien conocido es el vaciamiento de sí que se produce en la experiencia de las noches, un vaciamiento previo a la más alta experiencia de la unión, el matrimonio espiritual. "Si quieres serlo todo no quieras ser algo en nada", escribe el santo castellano. Y en otro lugar: "El que allí llega de vero / de sí mismo desfallece". El místico debe llegar al vacío completo de sí, "a la negatividad que es su reabsorción completa" para alcanzar "la positividad" de recibir un ser nuevo (un nuevo nombre, una nueva esencia) en Dios (dicho de otro modo: alcanzar "la supraexistencia por Dios" (cf. Henry Corbin, El hombre de luz, p. 130).

61 "En el Corán, la palabra tābūt aparece dos veces: 2, 249, donde se refiere al Arca de la alianza, 
Henry Corbin, así lo entendemos, ha expuesto magistralmente esa idea de bidimensionalidad, de bi-unidad ("la estructura de un ser con dos dimensiones"), que se fundamenta, como hemos visto, en la idea de hecceidad eterna ('ayn tâabita), y que permite la relación con Dios, un Dios cercano y a la vez trascendente ${ }^{62}$. El amor es lo que mejor lo expresa: "Somos dos espíritus inmanentes a un solo cuerpo", dice, refiriéndose al amor místico y al amor de una persona concreta, un comentador anónimo de Rūzbihān. "Un alma en dos cuerpos", es la expresión para el amor de amistad en San Agustín, inspirándose en un autor clásico. "Cuando el amante se ha convertido en la sustancia misma del amor, no hay ya contraposición de sujeto y objeto". "Hazte tan próximo a mí que llegue a pensar que tú eres yo", afirma Hallāăg. Cierto. No hay distinción en el sentido de distancia, separación, dualidad. Sí hay, entiendo yo, relación de dos que son uno; misteriosa, inseparablemente unidos. Y ciertamente, para llegar a ello, es preciso que antes ocurra "que el amante sea enteramente consumido en el amor y entonces él mismo es el amor", como también afirma Ḥallăğ.

Los versos de Ibn 'Arabī, en Fusūsu: «Alimenta con Dios a su Creación, pues tu ser es una brisa que se levanta, un perfume que Él exhala. Nosotros le hemos dado el poder de manifestarse por nosotros, mientras Él nos daba (el de existir por Él). Así el papel es compartido entre Él y nosotros». «Si Él nos ha dado la vida y existencia por su ser, yo le doy también la vida, conociéndole, en mi corazón» ${ }^{63}$.

Y comenta Henry Corbin: "Pero alimentar con Dios a sus criaturas es volver a investirlas de ese Dios, es por tanto hacer aflorar en ellas su estado teofánico; es lo que podemos designar como hacerse capaz de percibir la función angélica de los seres, investirlos con la dimensión angélica de su ser y quizá despertarlos a ella"64.

Permítasenos, antes de terminar, una breve reflexión metafísica, siguiendo a Corbin, pues la doctrina de la unidad del ser (wahdat al-wuğŭd) no implica un "monismo existencial", "sino una unidad trascendente del ser. El acto de ser no se diversifica en cuanto al sentido [Dios es uno, único], se mantiene único multiplicándose en actualidades de seres a los que hace ser: un sujeto incondicionado que nunca es hecho ser" ${ }^{95}$. En efecto, al margen de que la

mientras que en el versículo 20, 39 se trata del cofre en el que Moisés niño fue transportado por las aguas. En cuanto a la Sakinna, es mencionada cuatro veces (siempre con el verbo anzala, «hace descender»), y en tres de las cuatro ocasiones con la mención de las cohortes o ejércitos celestiales invisibles" (cf. El hombre y su ángel, p. 271, n. 49).

62 Gusta Henry Corbin de citar la frase de Meister Eckhart: "la mirada con la que yo le veo es la mirada con la que Él me ve" (por ejemplo en su libro ya citado El hombre de luz en el sufismo iranio, cf. p. 37). 63 Corbin, H., La imaginación creadora, pp. 154-155.

64 Id., p. 157.

65 Cf. Corbin, H., El hombre de luz, p. 128. 
palabra sujeto sea o no adecuada, esta concepción del acto de ser, que comparten Ibn 'Arabī, Tomás de Aquino y Mollā Sadrā, implica que Dios hace ser, da el ser, pero no es un ser; hace ver, pero no es visible. Éste me parece el sentido más hondo del wuğūd, que propicia el encuentro entre lo Real y lo creado, entre el Ser (o el puro Acto de Ser) y aquello que se caracteriza por su indigencia metafisica. Convertir a ésta en pobreza espiritual la revierte en "liberación absoluta de esa [su] indigencia". Ser para uno mismo no-ser es ser para Dios. Y "esta estación mística supone dar un sentido absoluto a la Ipseidad divina" (absolverla de toda relativización $)^{66}$.

"Contemplaba a mi doble celestial con mis ojos de luz", afirma Mani antes de morir ${ }^{67}$. Y nosotros, cuando despertemos, iremos al encuentro del Angel-guía, para atravesar el Puente. Entraremos en el Cielo de nuestro ser, allí donde germina el cuerpo de gloria preparado para el Día de la Resurrección. Una tierra y un cielo nuevos. Habiendo regresado del exilio, revestidos con la "túnica de la aurora", amanecemos a la Vida.

Invocar al ángel, escuchar su llamada, recorrer con él el camino sintiéndonos y sabiéndonos acompañados, protegidos, guiados... Esperarle al final, tras la iniciación de la muerte, como acabamos de sugerir, reconocerle en su luz, colaborar en la glorificación del cuerpo verdadero, real... Temblar, sobrecogerse en la belleza desbordante, hiriente y consoladora, mayestática... Y dormirse así en el olvido que es el recuerdo de nuestra verdadera Imagen; perdidos y encontrados, consumidos y renacidos. Sabiendo que somos y subsistimos -igual que toda la creación- tan sólo por el secreto.

66 Cf. id., p. 130.

67 El "hombre de luz", la "partícula de luz", nos lleva a considerar de nuevo la chispita (scintilla) de Eckhart; también la "rara perla muhammadiana", el séptimo órgano sutil de Simnānī. Como dice un maestro sufi, que Corbin no nombra: "Satanás se burla de todas tus amenazas. Lo que le espanta es ver una luz en tu corazón” (cf. Corbin, El hombre de luz, p. 81). 